\title{
Impacts of soil moisture on de novo monoterpene emissions from European beech, Holm oak, Scots pine, and Norway spruce
}

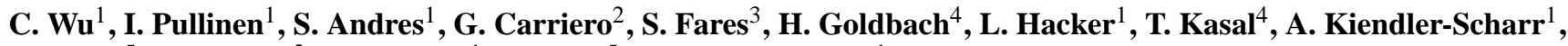 \\ E. Kleist ${ }^{5}$, E. Paoletti ${ }^{2}$, A. Wahner ${ }^{1}$, J. Wildt ${ }^{5}$, and Th. F. Mentel ${ }^{1}$ \\ ${ }^{1}$ Institut für Energie und Klimaforschung, IEK-8, Forschungszentrum Jülich, 52425 Jülich, Germany \\ ${ }^{2}$ Istituto Protezione Sostenibile Piante, Consiglio Nazionale Ricerche (CNR), Via Madonna del Piano10, \\ 50019 Sesto Fiorentino, Florence, Italy \\ ${ }^{3}$ Consiglio per la Ricerca e la sperimentazione in Agricoltura (CRA), Research Centre for the \\ Soil-Plant System, Rome, Italy \\ ${ }^{4}$ Department of plant nutrition (INRES), Universität Bonn, Karlrobert Kreiten Str. 13, 53115 Bonn, Germany \\ ${ }^{5}$ Institut für Bio- und Geowissenschaften, IBG-2, Forschungszentrum Jülich, 52425 Jülich, Germany
}

Correspondence to: J. Wildt (j.wildt@fz-juelich.de)

Received: 12 August 2014 - Published in Biogeosciences Discuss.: 9 September 2014

Revised: 24 November 2014 - Accepted: 25 November 2014 - Published: 9 January 2015

\begin{abstract}
Impacts of soil moisture on de novo monoterpene (MT) emissions from Holm oak, European beech, Scots pine, and Norway spruce were studied in laboratory experiments. The volumetric water content of the soil, $\Theta$, was used as the reference quantity to parameterize the dependency of MT emissions on soil moisture and to characterize the severity of the drought.

When $\Theta$ dropped from $0.4 \mathrm{~m}^{3} \times \mathrm{m}^{-3}$ to $\sim 0.2 \mathrm{~m}^{3} \times \mathrm{m}^{-3}$ slight increases of de novo MT emissions were observed but with further progressing drought the emissions decreased to almost zero. In most cases the increases of MT emissions observed under conditions of mild drought were explainable by increases of leaf temperature due to lowered transpirational cooling. When $\Theta$ fell below certain thresholds, MT emissions decreased simultaneously with $\Theta$ and the relationship between $\Theta$ and MT emissions was approximately linear. The thresholds of $\Theta\left(0.044-0.19 \mathrm{~m}^{3} \times \mathrm{m}^{-3}\right)$ were determined, as well as other parameters required to describe the soil moisture dependence of de novo MT emissions for application in the Model of Emissions of Gases and Aerosols from Nature, MEGAN.

A factorial approach was found appropriate to describe the impacts of $\Theta$, temperature, and light. Temperature and $\Theta$ influenced the emissions largely independently from each other, and, in a similar manner, light intensity and $\Theta$ acted independently on de novo MT emissions. The use of $\Theta$ as
\end{abstract}

the reference quantity in a factorial approach was tenable in predicting constitutive de novo MT emissions when $\Theta$ changed on a time scale of days. Empirical parameterization with $\Theta$ as a reference was only unsuccessful when soil moisture changed rapidly

\section{Introduction}

Biogenic volatile organic compounds (BVOC) are important atmospheric trace gases. They are involved in photochemical ozone- and particle-formation, and they impact the oxidation capacity of the troposphere (e.g. Chameides et al., 1988; Jacob and Wofsy, 1988; Derwent et al., 1996; Kulmala et al., 2004). On a global scale, the source strength of BVOC is estimated to be $\sim 1000 \mathrm{Tg}$ per year (Guenther et al., 1995, 2012) which exceeds the source strengths of anthropogenic volatile organic compounds by about an order of magnitude. The estimates of the global source strengths originate from model calculations which are often based on the same general procedure: BVOC emissions for standard conditions and for representative plant species (plant functional types) are used as basic model input. Dependencies of the BVOC emissions on variables such as temperature, light intensity $(\mathrm{PAR}=$ photosynthetic active radiation) and 
soil moisture are considered by applying phenomenological algorithms that describe the respective dependencies.

One of the first algorithms was developed by Tingey et al. $(1980,1991)$, who showed that monoterpene (MT) emissions from Slash pine exponentially depend on temperature but are independent of PAR. The underlying reason is that MT emissions from conifers originate from MT diffusion out of pools, which depends on temperature and not directly on PAR. In a modified syntax, Tingey's algorithm reads as follows:

$\Phi=\Phi^{\mathrm{S}} \times \exp \left(\beta \times\left(T-T_{\mathrm{S}}\right)\right)$.

In Eq. (1), $\Phi$ is the emission rate of the MT at the actual temperature $T, \Phi^{\mathrm{S}}$ is the standard emission rate or emission activity factor, i.e. the emission rate measured at standard temperature $T_{\mathrm{S}}$. $\beta$ is the parameter describing the temperature dependence. $\beta$ is in the range of $0.09 \mathrm{~K}^{-1}$.

Isoprene is emitted directly after its biosynthesis. Isoprene emissions thus are de novo emissions and directly related to the rate of isoprene biosynthesis. Biosynthetic activity generally depends on T and PAR. Hence, both variables are required to describe isoprene emissions as shown in the algorithm by Guenther et al. (1993). In a modified syntax, and neglecting decreases of isoprene emissions induced by high temperature stress (e.g. Guenther et al., 1993), the algorithm of Guenther et al. (1993) reads as follows:

$$
\Phi=\Phi^{\mathrm{S}} \times \frac{c_{\mathrm{L}} \times \alpha \times \mathrm{PAR}}{\sqrt{1+\alpha^{2} \times \mathrm{PAR}^{2}}} \times \exp \left(\beta \times\left(T-T_{\mathrm{S}}\right)\right) .
$$

In Eq. (2), $\Phi$ is the emission rate at temperature $T$ and at light intensity PAR. $\Phi^{\mathrm{S}}$ is the emission activity factor i.e. the emission rate measured at standard light intensity (often set to $1000 \mu \mathrm{mol} \times \mathrm{m}^{-2} \times \mathrm{s}^{-1}$ ) and at standard temperature, $T_{\mathrm{S}}$ (often set to $30^{\circ} \mathrm{C}$ ). $\alpha$ is the parameter describing the PAR dependence of the emission, and $c_{\mathrm{L}}$ is a normalization factor used to obtain $\Phi=\Phi^{S}$ when PAR is equal to the standard light intensity.

Equation (2) consists of three factors: first the emission activity factor, second the factor describing the PAR dependence and third the factor describing the temperature dependence. A factorial approach requires the individual factors to be independent of each other; i. e. Guenther et al. (1993) postulated that the PAR dependence is independent of the actual temperature and vice versa, that the temperature dependence is independent of the actual PAR.

Schuh et al. (1997) found interdependent impacts of temperature and PAR on MT emissions from sunflower which could not be described by a factorial approach as given in Eq. (2). They ascribed the observed interdependency to the two different mechanisms of MT emissions, MT emissions from pools that are independent of the actual light intensity and de novo emissions that depend on the actual light intensity. Depending on the species, both mechanisms can act in parallel. Schuh et al. (1997) suggested two additive terms to describe T and PAR dependence of MT emissions. One of them was similar to Eq. (2) and was used to describe de novo MT emissions. The other one was similar to Eq. (1) and describes the temperature dependence of MT emissions from pools. By using additive terms the factorial approach for de novo emissions was retained. This was confirmed by Shao et al. (2001) who used this algorithm to describe the emissions from Scots pine. Scots pine exhibits pure pool emissions, mixed pool and de novo emissions as well as a pure de novo emission (Kleist et al., 2012).

Schuh et al. (1997) noted the high variability of MT standard emission rates. Measuring emissions from different individuals of a given species under identical conditions of $T$ and PAR still resulted in highly variable emission rates. This clearly shows that MT emissions also depend on other variables than $\mathrm{T}$ and PAR alone. Among such other variables are leaf phenology, $\mathrm{CO}_{2}$ concentrations and soil moisture. We here focus on soil moisture.

In the Model of Emissions of Gases and Aerosols from Nature (MEGAN, Guenther et al., 2006, 2012), impacts of soil moisture are only considered for isoprene emissions. Guenther et al. (2006) implemented the empirical algorithm by Pegoraro et al. (2004) who used the volumetric water content, $\Theta$, as the reference quantity for characterizing the impacts of soil moisture. Three different regimes of $\Theta$ are used in MEGAN to define the factor that describes the impact of soil moisture on isoprene emissions. Above a threshold $\Theta_{1}$, isoprene emissions are not affected by soil moisture and the factor is unity. Below $\Theta_{1}$, isoprene emissions linearly decrease with decreasing $\Theta$ until the wilting point $\Theta_{\mathrm{W}}$ is reached. The wilting point $\Theta_{\mathrm{W}}$ is the soil moisture below which plants cannot extract water from the soil. At and below $\Theta_{\mathrm{W}}$ isoprene emissions are set to zero. In MEGAN, $\Theta_{\mathrm{W}}$ is taken from a database by Chen and Dudhia (2001). The difference: $\Theta_{1}-\Theta_{\mathrm{W}}, \Delta \Theta_{1}$, is the empirical parameter used to describe the dependence of isoprene emissions on soil moisture. Its value $\left(\Delta \Theta_{1}=0.06 \mathrm{~m}^{3} \times \mathrm{m}^{-3}\right)$ is taken from Pegoraro et al. (2004).

Compared to isoprene there are less studies on impacts of soil moisture on MT emissions. Some studies show increasing emissions with decreasing soil moisture (Bertin and Staudt, 1996; Blanch et al., 2007; Ormeño et al., 2007), others show decreasing emissions with increasing severity of drought (Lavoir et al., 2009; Šimpraga et al., 2011). Besides this, different reference quantities have been used to characterize the soil moisture level. Among these are the plant water potential (Ormeño et al., 2007; Lavoir et al., 2009) and the diurnal variation of the radial stem diameter (Šimpraga et al., 2011). As these plant parameters are highly variable between individuals and influenced by a larger number of factors, they can hardly be used for up-scaling.

Aim of our study was to provide data that can be used for modelling the impacts of soil moisture on de novo MT emissions with MEGAN. For this purpose we performed laboratory measurements with different plant species exposed to 
drought. We tested whether the volumetric water content $\Theta$ can be used as a reference quantity and whether a factorial approach is justified. Results of our experiments and the limitations of our approach are described below.

\section{Methods}

\subsection{Laboratory set up}

Experiments were performed at the Jülich Plant Atmosphere Chamber facility (JPAC). The setup of the chambers has already been described elsewhere in detail (e.g. Schimang et al., 2006; Mentel et al., 2009, 2013). The two plant chambers used for these experiments were made of borosilicate glass and operated as continuously stirred tank reactors (CSTR). To keep the temperature constant, the CSTRs were mounted in separate walk-in climate chambers. Each CSTR was equipped with a Teflon fan providing homogeneous mixing and diminishing the boundary layer resistance at leaf surfaces. The chambers were equipped with several connections to introduce temperature sensors (Newport Omega, HTMTSS), a light-intensity sensor (LI-COR, LI-189) and to connect the tubes for gas phase analysis and air supply.

For the experiments described here two plant chambers with volumes of 1150 and $164 \mathrm{~L}$ were used. The chambers were equipped with 11 and 7 discharge lamps (HQI 400 W/D; Osram, Munich, Germany), respectively, resulting in PAR at full illumination and at typical mid-canopy heights of 440 and $700 \mu \mathrm{mol} \times \mathrm{m}^{-2} \times \mathrm{s}^{-1}$, respectively. Infrared radiation (between 750 and $1050 \mathrm{~nm}$ ) from the lamps was reflected by filters (type IR3, Prinz Optics GmbH, Stromberg, Germany) placed between the lamps and the chambers in order to minimize radiative heating of the plants. To minimize wall losses, all tubes either consisted of Teflon (PTFE or PFA) or glass.

Ambient air was purified by an adsorptive drying device (Zander Aufbereitungstechnik $\mathrm{GmbH}$ and Co. KG, Essen, Germany, KEA 70) and by a palladium catalyst operating at $450^{\circ} \mathrm{C}$. Ozone, $\mathrm{NO}, \mathrm{NO}_{2}$, and volatile organic compounds $\left(>\mathrm{C}_{3}\right)$ were removed after the air had passed the purification system. Concentrations of $\mathrm{CO}_{2}$ and water vapour were also reduced by the adsorption dryer. $\mathrm{CO}_{2}$ was added to the inlet air to keep the $\mathrm{CO}_{2}$ concentrations similar to those in the environment. $\mathrm{CO}_{2}$ concentrations at plant chamber inlet were about $385 \mathrm{ppm}$. Uptake by the plants reduced the $\mathrm{CO}_{2}$ concentrations in the chamber to about $350 \mathrm{ppm}$ when the plants were well watered. Progressing drought caused lowered net photosynthesis and $\mathrm{CO}_{2}$ concentrations in the chamber increased near to those at chamber inlet. The air flow through the chambers was kept constant by mass flow controllers (Brooks Instruments). Typical air flows were in the range of $20-30 \mathrm{~L} \times \mathrm{min}^{-1}$ when using the small chamber and $50-100 \mathrm{~L} \times \min ^{-1}$ when using the large chamber.
Also the analytical equipment at JPAC is described in detail in previous publications (Schuh et al., 1997; Wildt et al., 1997; Schimang et al., 2006). $\mathrm{O}_{3}$ concentrations were measured by UV absorption (Thermo Environmental Instruments, model 49). Concentrations of NO were measured by chemiluminescence (Tecan, CLD 770 AL PPT) and for the measurements of $\mathrm{NO}_{2}$ the analysed air was led through a photolytic converter (Tecan, PLC 760). During all the measurements presented here, $\mathrm{O}_{3}$ mixing ratios were below $1 \mathrm{ppb} . \mathrm{NO}_{\mathrm{x}}$ mixing ratios were about $300 \mathrm{ppt}$.

Differences in mixing ratios of $\mathrm{H}_{2} \mathrm{O}$ and $\mathrm{CO}_{2}$ between chamber inlet and outlet were measured by IR absorption (Rosemount Binos 100 4P). Absolute $\mathrm{H}_{2} \mathrm{O}$ concentrations were determined with dew point mirrors (Walz, MTSMK1). Mixing ratios of BVOC were measured using gas chromatography-mass spectrometry (GC-MS, Agilent GCMSD-system HP5890 Series II + MS HP5972A, or GCMSD system HP6890 + HP5973, equipped with thermal desorption, TDSG, Gerstel, Mülheim, Germany). Calibration of the GC-MS systems was performed using a diffusion source containing pure chemicals in individual vials in combination with a dynamic dilution system. Concentrations of the compounds released from the calibration source were determined from the mass loss rates of the individual compounds and the dilution fluxes. The VOC mixing ratios were in the lower ppb to ppt range. For details on the GC systems and calibration procedure see, e.g. Heiden et al. (2003).

The CSTR contained shoots and leaves of the plants. The upper part of the setup was separated from the lower part containing roots and soil by PTFE sheets with a hole at the centre to accommodate the stem. The stem duct was closed by a flexible bag.

The pot containing the plants' roots was positioned in a shallow dish allowing for collecting excess water from the pot. Plant, pot, and dish were mounted on a balance (Sartorius, MC1) that was used to measure the weight of the investigated plant together with the soil and the water in the soil. The flexibility of the bag that sealed the gap between stem and stem duct allowed weighing the plant/soil system on-line. The balance had a nominal resolution of $1 \mathrm{~g}$, but variations of the chamber's slight overpressure (5-10 mbar) imposed noise in the range of $20-30 \mathrm{~g}$ limiting the precision of weight measurements.

\subsection{Determination of flux densities}

Flux densities for the compound $X, \Phi(X)$, were calculated using the respective differences of the mixing ratios between chamber inlet and outlet and the leaf area, $A_{\text {leaf }}$, as the basis:

$\Phi(X)=\frac{F_{\text {air }} \times\left([X]_{\mathrm{i}}-[X]\right)}{A_{\text {leaf }}}$.

In Eq. (3), $F_{\text {air }}$ is the air flow through the chamber (in units of mol s$\left.{ }^{-1}\right),[X]_{\mathrm{i}}$ is the mixing ratio of compound $X$ at chamber inlet and $[X]$ is the mixing ratio of compound $X$ in the 
Table 1. List of experiments and chamber settings.

\begin{tabular}{|c|c|c|c|c|}
\hline Plant & $\begin{array}{l}\text { Purpose of } \\
\text { experiment }\end{array}$ & $\begin{array}{l}\text { Leaf area } \\
\qquad\left(\mathrm{m}^{2}\right)\end{array}$ & $\begin{array}{l}\text { Chamber temp- } \\
\text { erature }\left({ }^{\circ} \mathrm{C}\right)\end{array}$ & $\begin{array}{c}\text { PAR } \\
\left(\mu \mathrm{molm}{ }^{-2} \mathrm{~s}^{-1}\right)\end{array}$ \\
\hline European beech & $\Theta$-dependence & 0.91 & 23 & 440 \\
\hline Holm oak 1 & $\Theta$-dependence & 0.25 & 25 & 600 \\
\hline Holm oak 2 & $\Theta$-dependence & 0.27 & 22 & 440 \\
\hline Norway spruce & $\Theta$-dependence & 0.7 & 23 & 440 \\
\hline Scots pine & $\Theta$-dependence & 0.45 & 25 & 400 \\
\hline Holm oak 3 & $\Theta$ - and $T$-dependence & 0.18 & 15 & 500 \\
\hline Holm oak 3 & $\Theta$ - and $T$-dependence & & 20 & 500 \\
\hline Holm oak 3 & $\Theta$ - and $T$-dependence & & 25 & 500 \\
\hline Holm oak 4 & $\Theta$ - and PAR-dependence & 0.25 & 20 & 700 \\
\hline Holm oak 4 & $\Theta$ - and PAR-dependence & & 20 & 400 \\
\hline Holm oak 4 & $\Theta$ - and PAR-dependence & & 20 & 200 \\
\hline
\end{tabular}

chamber. Flux densities are termed as MT emission rates for $X=\mathrm{MT}$, transpiration rates for $X=\mathrm{H}_{2} \mathrm{O}$, and net assimilation rates for $\mathrm{X}=\mathrm{CO}_{2}$. According to the results of several tests (e.g. Schuh et al., 1997; Heiden et al., 2003; Schimang et al., 2006), wall losses and chemical reactions were unimportant for all compounds investigated here and were therefore neglected. As convention, flux densities are positive when compounds are emitted (e.g. water, MT) and negative when compounds are taken up (e.g. $\mathrm{CO}_{2}$ ). To allow better visual comparison in diagrams, net assimilation is multiplied by -1 .

Stomatal conductance was calculated using Eq. (4).

$\mathrm{c}\left(\mathrm{H}_{2} \mathrm{O}\right)=\frac{\phi\left(\mathrm{H}_{2} \mathrm{O}\right)}{\Delta\left[\mathrm{H}_{2} \mathrm{O}\right]}$

Herein, $\Delta\left[\mathrm{H}_{2} \mathrm{O}\right]$ is the difference between water vapour mixing ratios in the substomatal cavity and in the chamber air, the former calculated from leaf temperature assuming saturation vapour pressure in the substomatal cavity.

After finishing an experiment, about $5 \%$ of the leaves from broadleaf species were dissected from the plant, taking care to select representative leaves. The leaves were scanned for leaf area determination and evaluated by image analysis. Total leaf area was calculated by multiplying the averaged area measured per dissected leave by the total number of leaves.

Needle area for the conifers were determined as described in Shao et al. (2001). The number of needles per $10 \mathrm{~cm}$ of branches with green needles was counted for representative branches, needles were removed from these branches, scanned and the area of dark pixels was determined. Upscaling from the measured needle area to the total needle area was performed by considering the total lengths of branches with green needles for the respective conifer.

Uncertainty in leaf/needle area determination was estimated to be approximately $10 \%$. Note that the needle areas given in Table 1 are projected needle areas and leaf areas for broadleaf species are one-sided leaf areas.

\subsection{Experiments with plants}

Experiments were conducted with individual plants using species representative for European climate zones. European beech (Fagus sylvatica L.) and Holm oak (Quercus ilex L.) represented species without storage pools for monoterpenes. Scots pine (Pinus sylvestris L.) and Norway spruce (Picea abies L.) mainly exhibited MT pool emissions but also showed de novo MT emissions.

In total seven plants were used for the measurements: one individual each for beech, spruce, and pine and four individuals of Holm oak. One to two-year old beech-, pine, and spruce-seedlings were taken from the forest, potted in buckets of $15 \mathrm{~L}$ volume and stored outside for about a year before they were used for the experiments. Seedlings of Holm oak were obtained from the forest nursery of the Castelporziano estate, Rome, central Italy. These have been successively potted in $15 \mathrm{~L}$ buckets and stored for several weeks in a growth room before using them in the CSTR. All plants were potted in the same soil that was a mix of peat (Einheitserde ED73 containing $2 \mathrm{~g} \times \mathrm{L}^{-1}$ nutrient salts and $1 \mathrm{~g} \times \mathrm{L}^{-1}$ clay) with quartz sand, volumetric ratio $5: 1$, density $0.46 \pm 0.07 \mathrm{~kg} \times \mathrm{L}^{-1}$.

To control for the de novo nature of the 1,8-cineol emission from the conifers we exposed the plants to ${ }^{13} \mathrm{CO}_{2}$. The chamber was flushed with synthetic air (Air Liquide, Germany) and ${ }^{13} \mathrm{CO}_{2}\left(99 \%{ }^{13} \mathrm{C}, \sim 350 \mathrm{ppm}\right)$ was added for $\sim 3 \mathrm{~h}$ in each of both experiments.

Individual plants were investigated for time periods of 310 weeks. In most of our studies, the impact of soil moisture was investigated (Table 1, European beech, two experiments with Holm oak - experiment Holm oak 1 and Holm oak 2 - one experiment with Norway spruce and one with Scots pine). In these experiments the plants were exposed to a diurnal rhythm of $11 \mathrm{~h}$ illumination and $11 \mathrm{~h}$ darkness, and simulation of twilight by switching on or off individual lamps within $1 \mathrm{~h}$ in the morning and evening, respectively. 


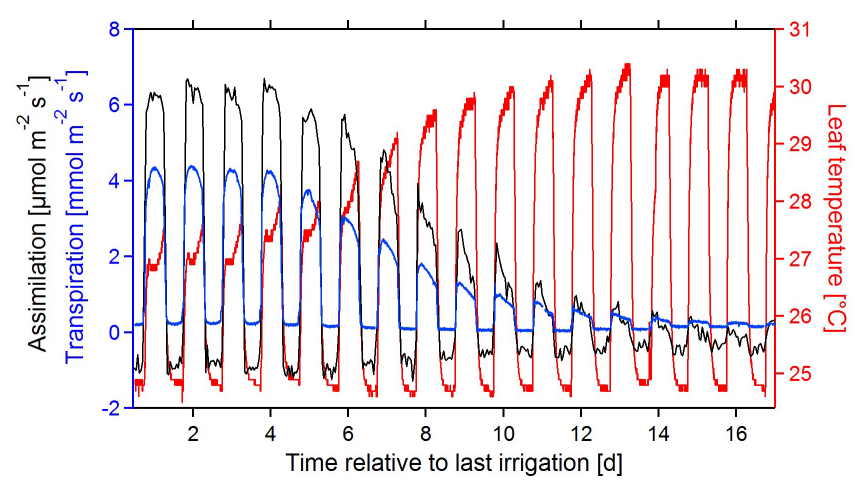

Figure 1. Temporal development of transpiration (blue trace, left hand $y$ axis) and leaf temperature (red trace, right hand $y$ axis, average of three leaves) at the example of Holm oak, experiment 1 . The plant was irrigated at day $0\left(\Theta=0.4 \mathrm{~m}^{3} \times \mathrm{m}^{-3}\right)$. At the end of the drought period $\Theta$ had fallen to $0.05 \mathrm{~m}^{3} \times \mathrm{m}^{-3}$. Chamber temperature $25^{\circ} \mathrm{C}, \mathrm{PAR}=600 \mu \mathrm{mol} \mathrm{m} \mathrm{s}^{-2} \mathrm{~s}^{-1}$.

In additional studies, we varied $T$ or PAR, respectively, in parallel to soil moisture to investigate the potential limitations of the factorial approach. In the third experiment with Holm oak the chamber temperature was systematically changed during periods of illumination. Except for 2 days, the chamber temperature was set to $15^{\circ} \mathrm{C}$ during the night and kept at $15^{\circ} \mathrm{C}$ for the next $6-7 \mathrm{~h}$ of the following illumination period (from $3 \mathrm{o}^{\prime}$ 'clock to $\sim 10$ o'clock). Then the temperature was set to $20^{\circ} \mathrm{C}$ for 4 hours (from $\sim 10$ to $\sim 14$ o'clock) and thereafter to $25^{\circ} \mathrm{C}$ (from $\sim 14$ to $\sim 18$ o'clock, all data local time). The exact timing of temperature settings was adapted to the start of GC runs. The period of illumination was elongated to $15 \mathrm{~h}$ allowing measuring at the three different temperatures, but at the same PAR for each day. When $\Theta$ had fallen below $0.02 \mathrm{~m}^{3} \times \mathrm{m}^{-3}$, the systematic temperature variations were interrupted for 2 days to follow the drought-induced decrease of MT emissions without changes of temperature and PAR. After these 2 days, the chamber temperatures were again varied in the same manner as before these days.

In the fourth experiment with Holm oak, PAR was changed systematically during periods of illumination. Every second day PAR was set to $700 \mu \mathrm{mol} \mathrm{m}^{-2} \mathrm{~s}^{-1}$ for $6 \mathrm{~h}$ (from 4 o'clock to $\sim 10$ o'clock), thereafter to $400 \mu \mathrm{mol} \mathrm{m}^{-2} \mathrm{~s}^{-1}$ for $5 \mathrm{~h}$ (from $\sim 10$ to $\sim 15$ o'clock), and then to $200 \mu \mathrm{mol} \mathrm{m}^{-2} \mathrm{~s}^{-1}$ for $5 \mathrm{~h}$ (from $\sim 15$ to $\sim 20$ o'clock). From $\sim 20$ o'clock to 4 o'clock PAR was zero. During the other days, PAR was held constant at $400 \mu \mathrm{mol} \mathrm{m}^{-2} \mathrm{~s}^{-1}$ from 4:00 to 20:00 LT. Table 1 lists the experiments and the respective conditions of PAR and chamber temperatures.

Due to the radiation from the lamps, the chamber temperatures and the leaf temperatures varied with illumination. During periods of darkness leaf temperatures and chamber temperatures were similar. During periods of illumination leaf temperature was higher than chamber temperature. For well watered plants leaf temperature was about $2{ }^{\circ} \mathrm{C}$ higher than the chamber temperature. Progressing drought stress decreased transpiration and leaf temperatures increased by additional $2-3{ }^{\circ} \mathrm{C}$ relative to the chamber temperature (Fig. 1).

\subsection{Determination of $\Theta$ and the $\Theta$-dependence of MT emissions}

The volumetric water content, $\Theta$, was determined from the mass loss of water during the respective experiments (Eq. 5).

$\Theta=\frac{M_{\text {act }}-M_{\text {dry }}}{V_{\text {soil }}} \times \frac{1}{\rho}$

In Eq. (5), $M_{\text {act }}$ is the actual mass of the soil and $M_{\text {dry }}$ is the dry mass of the soil. $V_{\text {soil }}$ is the volume of the soil in the pots neglecting the volume of the roots. $M_{\text {act }}$ was measured online and $M_{\text {dry }}$ was estimated from soil samples taken from the top of the pots and oven-dried at $110^{\circ} \mathrm{C}$ for 5 days. The measured mass loss was converted to volume loss by using a water density, $\rho$, of $1 \mathrm{~kg} \mathrm{~L}^{-1}$.

The dependence of MT emission on $\Theta$ was parameterized in the following manner: maximum MT emissions were reached when $\Theta$ had fallen near to the threshold below which MT emissions started to decrease $\left(\Theta_{1}\right)$. The average of the emission rates measured around the maximum emissions was set as standard emission rate, $\Phi^{\mathrm{S}}$. Emission rates measured at the same light intensity and chamber temperature were normalized by dividing them by $\Phi^{\mathrm{S}}$. The normalized data were used to determine the relationship between MT emissions and $\Theta$. Although the decrease of emissions with decreasing $\Theta$ appeared to be exponential, we applied a linear approximation to be comparable to other parameterization approaches. Linear fits to the normalized data allowed to determine $\Theta_{1}$ as well as the volumetric water content $\Theta_{0}$ below which the extrapolated emissions became zero. Only data with $\Theta<\Theta_{1}$ and measured at the same PAR and the same chamber temperature were taken for fitting. Furthermore, all data where $\Phi / \Phi^{\mathrm{S}}<0.05$ were discarded to diminish the impact of the exponential behaviour. Similar to the notation used in MEGAN, we calculated $\Delta \Theta_{1}$, the difference $\Theta_{1}-\Theta_{0}$. This procedure of determining the $\Theta$ dependence of MT emissions was performed for all data sets.

\subsection{Error determination and conversion from $\Theta$ to RWC}

Experimental errors in the determination of $\Theta$ were due to the noise on $M_{\text {act }}$, due to the uncertainties of $M_{\text {dry }}$ and due to the error in the determination of $V_{\text {soil }}$. The error in volume determination was negligible and, compared to the error in $M_{\text {dry }}$, the error by the noise was of minor importance. The statistical noise of $20-30 \mathrm{~g}$ (peak to peak noise, deviation from average at maximum $\pm 15 \mathrm{~g}$ ) added an uncertainty of $\pm 15 \mathrm{~mL}$ to the volume of water, which is low compared to the total amount of added water $(5-6 \mathrm{~L})$. At soil volumes 
of about $13 \mathrm{~L}$, the uncertainty produced by the noise on $\Theta$ was $\pm 0.0012 \mathrm{~m}^{3} \times \mathrm{m}^{-3}$.

The error due to our procedure of taking soil samples was higher. Taking samples from the same pot caused differences in the dry mass. Extrapolated to the total mass of the soil, the maximum deviation was $420 \mathrm{~g}$, leading to an uncertainty of $\pm 210 \mathrm{~g}$ for $M_{\text {dry }}$. This is more than an order of magnitude higher than the uncertainty added by the noise on $M_{\text {act }}$. The uncertainty we give for $\Theta$ is therefore mainly based on the uncertainty of $M_{\text {dry }}$ which, converted to the water volume is $\pm 210 \mathrm{~mL}$. The possible error added to $\Theta$ by the uncertainty of $M_{\text {dry }}$ is: $\pm 0.016 \mathrm{~m}^{3} \mathrm{~m}^{-3}$.

It has to be noted that the error caused by the different error sources have different qualities; while errors due to the noise are statistical errors, the error caused by uncertainty of $M_{\text {dry }}$ is a systematic error for each individual experiment. Errors in $M_{\text {dry }}$ mainly cause a systematic shift of the $\Theta$ axis. Errors in the zero point may therefore be high and in one case, the measured $M_{\text {act }}$ was lower than $M_{\text {dry }}$. This led to slightly negative values for $\Theta$ which is physically impossible. However, since the deviation from zero was quite low, we left the negative values.

Erroneous determination of $M_{\text {dry }}$ does not impose important uncertainties on $\Delta \Theta_{1}$. Due to the systematic nature of this error, its main effect is a systematic shift of the $\Theta$ axis. As $\Delta \Theta_{1}$ is the difference between $\Theta_{1}$ and $\Theta_{0}$, systematic shifts in $\Theta$ cancel out. Hence, total uncertainties in $\Delta \Theta_{1}$ which is the main parameter for modelling with MEGAN were quite low and thus acceptable.

Besides uncertainties of $\Theta$ caused by errors in the determination of $M_{\text {act }}$ and $M_{\text {dry }}$, there is also an uncertainty due to our fitting procedure. Also MT emissions contain uncertainties and hence, data obtained from fits using the MT emissions as base conserve these uncertainties. Nevertheless, the statements we give on the soil moisture dependence of MT emissions and on the differences observed with this respect between MT emissions on the one hand and net photosynthesis and transpiration on the other hand are not substantially affected by the errors in $\Theta$.

To allow using our data also for models that use the relative water content of the soil as reference we give a conversion factor from $\Theta$ to RWC. According to Rambal et al. (2003), RWC is the ratio of current water content to water content at field capacity. Using our mass based data, RWC can be calculated according to Eq. (6):

$\mathrm{RWC}=\frac{M_{\mathrm{act}}-M_{\mathrm{dry}}}{M_{\mathrm{FC}}-M_{\mathrm{dry}}}$.

In Eq. (6), $M_{\mathrm{FC}}$ is the mass of the soil at field capacity, $M_{\mathrm{act}}$ is the actual mass and $M_{\text {dry }}$ the dry mass as in Eq. (5). Field capacity is reached when the micropores of the soil are filled with water and the macropores filled with air after water is lost by gravity. According to our procedure of waiting some hours before measuring the weight of pot and plant, the water in the macropores should have been lost. We therefore

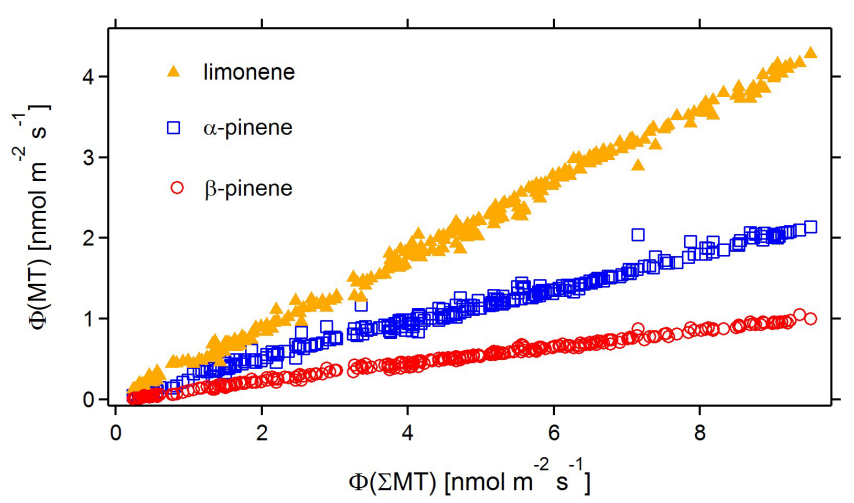

Figure 2. Correlation plot of emission rates measured for Holm oak, experiment 2. Only data measured at a PAR of $440 \mu \mathrm{mol} \mathrm{m} \mathrm{m}^{-2} \mathrm{~s}^{-1}$ and a chamber temperature of $22^{\circ} \mathrm{C}$ are plotted. The variation of emission rates is caused by changes in soil moisture. The high coefficients of determination $\left(R^{2}>0.95\right)$ indicate that only the strengths of the emissions was changed but not the emission pattern.

approximate $M_{\mathrm{FC}}$ from the weight shortly after removing the excess water from the dishes below the pots and after subtracting the mass of the empty pot. Setting RWC $=x \times \Theta$ it follows:

$x=\frac{V}{M_{\mathrm{FC}}-M_{\mathrm{dry}}} \times \rho$.

As factor pooled from all measurements we obtained $x=2.6 \mathrm{~kg} \times \mathrm{kg}^{-1} \times \mathrm{m}^{-3} \times \mathrm{m}^{3}$ if soil water content is measured in $\mathrm{kg}\left(\mathrm{H}_{2} \mathrm{O}\right)_{\text {act }} \times \mathrm{kg}\left(\mathrm{H}_{2} \mathrm{O}\right)_{\mathrm{FC}}^{-1}$. Note that the conversion factor is only valid for our type of soil and cannot be transferred to other experiments or field conditions.

\section{Results}

\subsection{Emission patterns}

All investigated plants emitted monoterpenes (MT) while emissions of isoprene and sesquiterpenes were low, if detectable at all. Neither stress-induced emissions of phenolic volatiles originating downstream of the shikimate pathway nor stress-induced emissions originating from the octadecanoid pathway were observed. Even for drought-stressed plants such non-MT emissions were absent indicating that the plants did not substantially suffer from other unintended stresses than drought.

The MT emission patterns were constant for each individual Holm oak and European beech. Relating the emission rates of a given MT to those of other MT (cross correlations) emitted from the same plant yielded significant correlations with coefficients of determination always above $R^{2}>0.95$ (Fig. 2). On the one hand the high correlation showed that all MT had the same basic emission mechanism: all of them were de novo emissions. On the other hand, the 


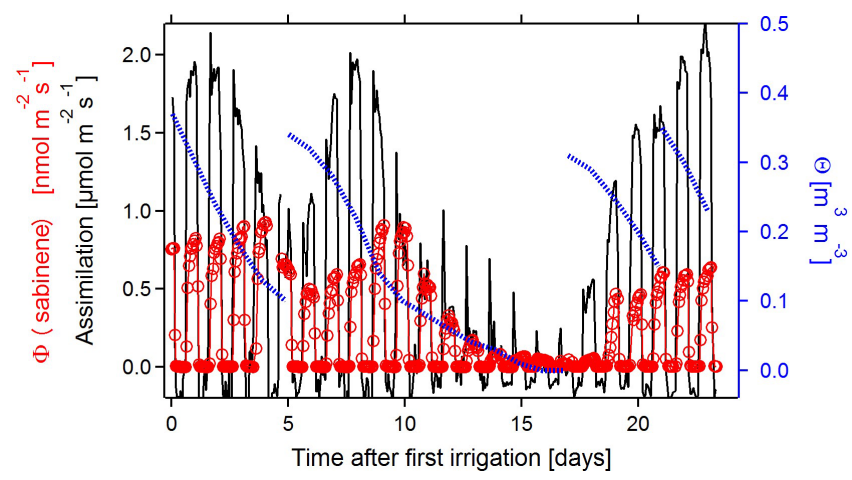

Figure 3. Long term time series of sabinene emissions from a European beech seedling (red circles, left hand $y$ scale), assimilation (multiplied by -1 , black line, left hand $y$ scale) and volumetric water content of the soil $\Theta$ (blue dashed line, right hand $y$ scale).

excellent correlation was obtained including the data during severe drought. This implies that for a given plant the impacts of drought were exactly the same for emissions of each individual MT species. Therefore the effects of drought on de novo MT emissions can be shown at the example of a single MT.

Sabinene was the dominant emission from European beech, comprising nearly $1 / 3$ of the total emissions. Other MT emitted in substantial amounts were the following: $\gamma$ terpinene, $\alpha$-terpinene, $\beta$-phellandrene, and $\alpha$-terpinolene. We will show the response of European beech to drought at the example of sabinene. Main MT emissions from Holm oak were those of $\alpha$-pinene, limonene, $\beta$-pinene, sabinene and myrcene. In two of the experiments with Holm oak $\alpha$ pinene was the dominant emission (experiment 1: $\sim 48 \%$ of total MT emissions; experiment 3: $\sim 42 \%$ of total MT emissions), in the two other experiments the emissions of limonene were the strongest (experiment 2: limonene $\sim 45 \%, \alpha$-pinene $\sim 23 \%$ of total MT emissions; experiment 4: limonene $\sim 39 \%, \alpha$-pinene $\sim 25 \%$ of total MT emissions). To demonstrate the behaviour of MT emissions from Holm oak in response to drought we choose $\alpha$-pinene as pivotal substance. It has to be noted that strong emissions of the acyclic ocimenes have been absent from Holm oaks. Emissions of ocimenes may show different behaviour than emissions of the cyclic MT (Staudt and Bertin, 1998). On the one hand, correlations as shown in Fig. 2 may be disturbed in the presence of strong ocimene emissions. On the other hand we cannot report on the drought impacts on ocimene emissions which may be different from that shown here for the cyclic MT. During our experiments, the ocimene emissions were too low to significant influence the sum of all MT emissions (maximum $\sim 6 \%$ of total MT emissions).

For spruce and pine cross correlations as shown in Fig. 2 were useless. Both conifers exhibited pure pool emissions, mixed pool and de novo emissions as well as one pure de novo emission (compare Shao et al., 2001; Kleist et al.,
2012). The only pure de novo MT emission was that of $1,8-$ cineole. We therefore show only the data we obtained for 1,8 -cineole although these emissions made only a minor contribution to the total emissions. For spruce the emissions of 1,8 -cineole contributed to less than $1 \%$ to the total, for pine they contributed to about $10 \%$ to the total MT emissions.

\subsection{Impacts of soil moisture}

\subsubsection{European beech}

Figure 3 shows the time series of sabinene emissions from European beech over a period of about 3 weeks. According to the de novo nature of the emissions a significant diurnal variation was observed with nearly no emissions during darkness and high emissions during periods of illumination. As can be seen in the $\Theta$-trace, the plant was watered 4 times during the experiments. Between 2.5 and $5.6 \mathrm{~L}$ water were added after soil moisture had reached values of $\Theta \sim 0.1 \mathrm{~m}^{3} \times \mathrm{m}^{-3}$ (dry conditions) and $\Theta$ near to $0 \mathrm{~m}^{3} \times \mathrm{m}^{-3}$ (severe drought), respectively.

In addition to the strong light-dependent variation, impacts of soil moisture on MT emissions were also observable. During severe drought (2nd period, days 5-17 in Fig. 3) MT emissions decreased near to zero. After re-watering, MT emissions increased again. Such increases were not instantaneous but appeared on a time scale of few days.

Transpiration (not shown in Fig. 3) and net assimilation showed similar responses to $\Theta$ as MT emissions but with different response times. As can be seen, changes in net assimilation appeared earlier than changes in MT emissions, in particular during the phase of the second drought period (Fig. 3, days 5-17).

Figure 4 shows the dependence of normalized sabinene emissions and net assimilation on $\Theta$. Only data taken at $\mathrm{PAR}=440 \mu \mathrm{mol} \times \mathrm{m}^{-2} \times \mathrm{s}^{-1}$ are shown. For $\Theta$ between 0.35 and $0.1 \mathrm{~m}^{3} \times \mathrm{m}^{-3}$, MT emissions showed a considerable scatter that was mainly caused by different response times for the emissions to increase to pre-drought levels. With $\Theta$ falling below $0.1 \mathrm{~m}^{3} \times \mathrm{m}^{-3}$ emissions decreased to minute amounts. As obvious from Fig. 4, changes of net assimilation as response to decreasing soil moisture were different from those of MT emissions. Net assimilation already decreased at higher $\Theta$ of $\sim 0.22 \mathrm{~m}^{3} \times \mathrm{m}^{-3}$.

\subsubsection{Holm oak}

Two experiments with Holm oak were set up to investigate whether the reduction of MT emissions with decreasing $\Theta$ was determined by the soil moisture or by some other time constant of the plant itself (Table 1, experiment Holm oak 1 and Holm oak 2, temporal shape of $\alpha$-pinene emissions, assimilation and $\Theta$ see Supplement Fig. S1). Holm oak 1 was investigated at higher PAR and at higher $T$ and showed higher rates of net photosynthesis and higher transpiration 


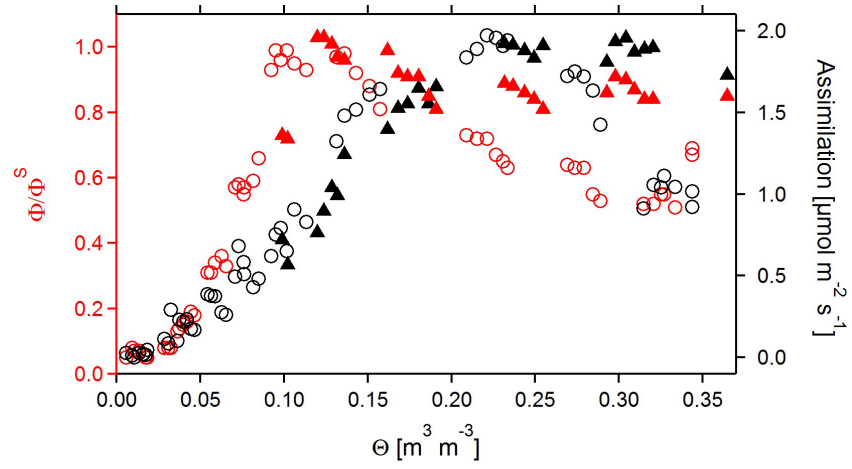

Figure 4. Normalized sabinene emissions from beech (red symbols, left scale) and rates of net photosynthesis (black symbols, right scale, multiplied by -1 ) in dependence on $\Theta$. Closed triangles represent data taken during a first drought period that was stopped when $\Theta$ had fallen to $0.1 \mathrm{~m}^{3} \times \mathrm{m}^{-3}$ (days $0-5$ in Fig. 3), open circles represent data taken during the following period of recovery (days 6-10 in Fig. 3) until the end of the severe drought at day 17. Only data taken at a chamber temperature of $23^{\circ} \mathrm{C}$ and a PAR of $440 \mu \mathrm{mol} \mathrm{m}^{-2} \mathrm{~s}^{-1}$ are considered.

(data not shown). The soil and the plant roots were also exposed to higher temperatures than Holm oak 2. Due to the combination of higher evaporation and transpiration rates, $\Theta$ dropped from $\sim 0.12 \mathrm{~m}^{3} \times \mathrm{m}^{-3}$ to $\sim 0.03 \mathrm{~m}^{3} \times \mathrm{m}^{-3}$ within 8 days, faster than for Holm oak 2 where it took about 18 days.

The MT emissions decreased also on different time scales in the two experiments (see Fig. 5a). In contrast, the decrease of MT emissions with decreasing $\Theta$ was similar for both individuals although they were investigated at different dynamics of drought progression (Fig. 5b). The substantial difference observed for the temporal behaviour of the emissions (Fig. 5a) did not cause significant changes in decrease of emission rates for $\Theta<0.1 \mathrm{~m}^{3} \times \mathrm{m}^{-3}$ (Fig. 5b). Similar as for beech, increasing MT emissions were observed for Holm oak when $\Theta$ declined from $\sim 0.4$ to $0.15 \mathrm{~m}^{3} \times \mathrm{m}^{-3}$. For Holm oak 1, at higher $T$ and PAR, the emissions increased nearly threefold. For Holm oak 2 the increase was about $40 \%$.

In the third experiment with Holm oak chamber temperature was changed systematically during the progressing drought (Table 1, experiment Holm oak 3). This experiment was designed to measure the impact of $\Theta$ on MT emissions at different temperatures as well as the temperature dependence at different stages of drought.

The temperature dependence of MT emissions was determined by linear regression analysis of $\ln (\Phi)$ versus leaf temperatures (see Eq. 1 or Eq. 2 third factor). During the first 9 days with varying temperature at $\Theta>0.1 \mathrm{~m}^{3} \times \mathrm{m}^{-3}$ the temperature dependence remained constant with $\beta=$ $0.12 \pm 0.007 \mathrm{~K}^{-1}$ (mean, $1 \sigma$ standard deviation).
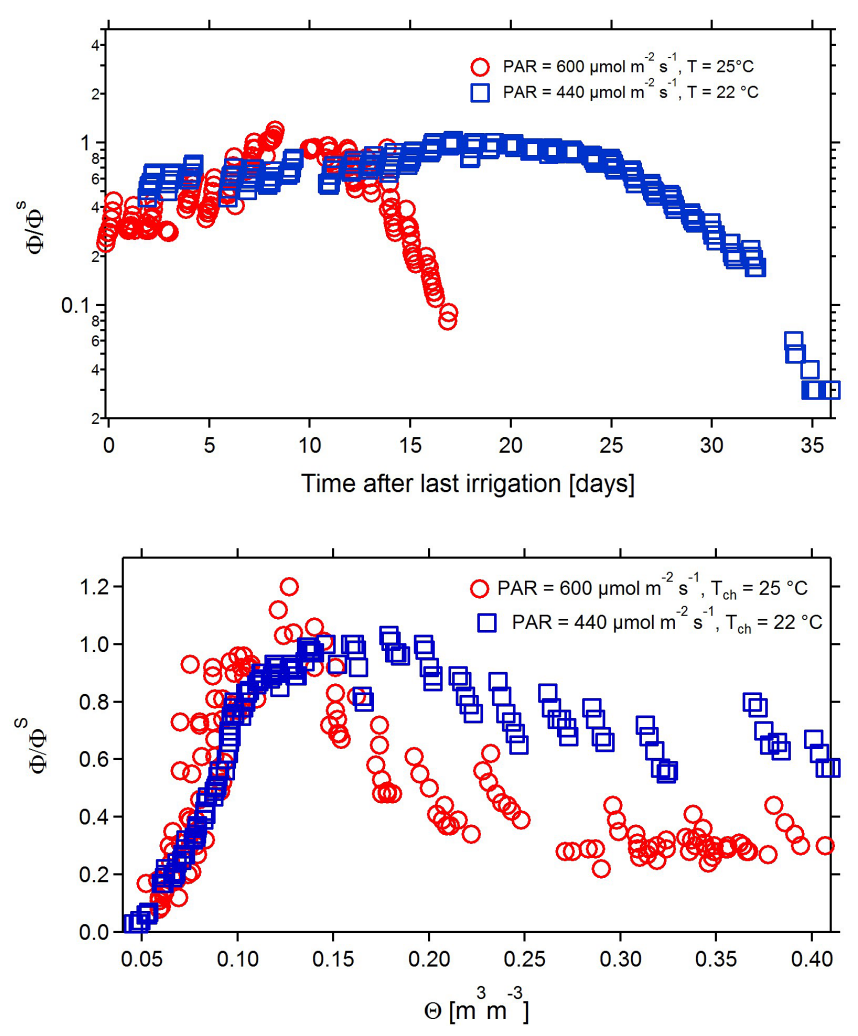

Figure 5. (a) Temporal shape of normalized $\alpha$-pinene emissions from two individuals of Holm oak, experiments Holm oak 1 and Holm oak 2. Red circles show the data obtained at higher PAR and at higher chamber temperature. Blue squares show the data obtained for the plant investigated at lower temperature and PAR. Only data taken during periods of full illumination are shown. For better comparison the emissions were separately normalized to the emission rates measured for the respective individual at $\Theta \sim 0.12 \mathrm{~m}^{3} \times \mathrm{m}^{-3}$. (b) Normalized $\alpha$-pinene emissions from Holm oak in dependence of $\Theta$. Red circles show the data measured for the plant investigated at higher PAR and higher chamber temperature, blue squares show data taken for the plant investigated at lower PAR and lower temperature. Same data as in (a).

Similar to the observations in the other experiments with Holm oak, MT emissions decreased when $\Theta$ fell below $0.06 \mathrm{~m}^{3} \times \mathrm{m}^{-3}$. During this measurement period the impacts of progressing drought and variations of temperature superimposed each other. Although temperature increased systematically over the day, emissions did not increase substantially. Consistent with the findings reported by Bertin and Staudt (1996). In the raw data typical log-linear relationships between emissions and temperature were not easily observable. We therefore had to remove the drought-induced decrease of MT emissions over the day.

Approaches to determine the $\Theta$ dependence from the data obtained at the days when temperature was held constant were not successful. The small dynamic range in which $\Theta$ changed during these 2 days (from $\sim 0.025$ to 


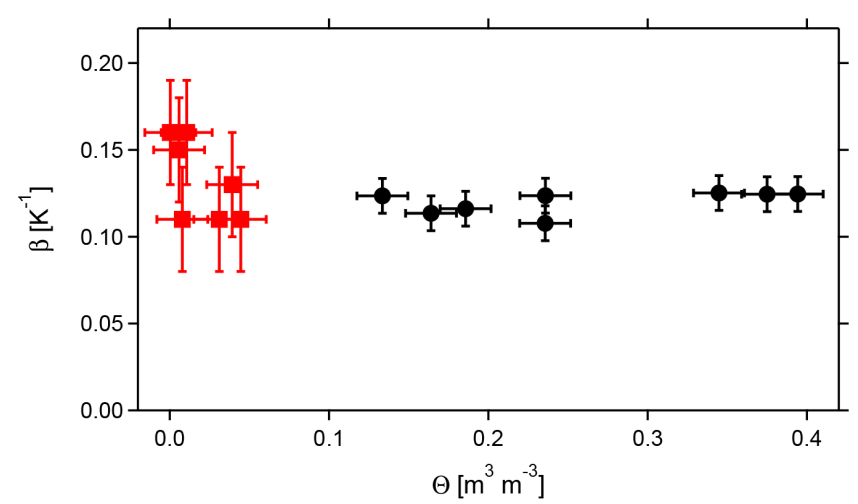

Figure 6. Temperature coefficient $\beta$ for $\alpha$-pinene emissions from Holm oak (experiment 3) at different soil moisture. Black circles represent the data obtained without impacts of drought on MT emissions. Red squares represent the data obtained for $\Theta<0.06 \mathrm{~m}^{3} \times \mathrm{m}^{-3}$ after correcting for the drought-induced decrease of emissions. Errors in $\beta$ were about $\pm 0.01 \mathrm{~K}^{-1}$ for the data obtained without drought stress. For the data obtained during drought stress the errors from the normalization procedure had to be taken into account and errors in $\beta$ are estimated to be $\pm 0.03 \mathrm{~K}^{-1}$. Error in $\Theta$ is estimated to be $\pm 0.016 \mathrm{~m}^{3} \times \mathrm{m}^{-3}$.

$\sim 0.013 \mathrm{~m}^{3} \times \mathrm{m}^{-3}$ ) prevented a reliable analysis. On the other hand, the assumed linear decrease of MT emissions with decreasing $\Theta$ is only an approximation because the decrease appeared to be exponential (compare Figs. 4, 5b). We therefore directly used the temporal decay of the emissions during the 2 days when temperature and PAR were held constant to develop the drought correction considering that the temporal decay of emissions reflects the decay in $\Theta$ (compare Fig. 5a and b).

An exponential function was fitted to the temporal decay measured during the respective days yielding a decay rate of $0.04 \pm 0.002 \mathrm{~h}^{-1}, R^{2}=0.85$. The correction factor was set to 1 for the time when the chamber had reached steady state conditions after twilight in the morning. Correction factors were then calculated for each time when the chromatograms were taken by using the decay rate of $0.04 \mathrm{~h}^{-1}$. The emission rates determined for the respective times were then divided by the correction factor which dropped from 1 in the morning to $\sim 0.6$ in the evening. Data corrected for the droughtinduced decrease were used to determine the temperature coefficient $\beta$ during periods with low soil moisture.

Figure 6 shows the values obtained for $\beta$ in dependence of $\Theta$. As the decay rate of 0.04 per hour was not applicable for $\Theta$ near to $\Theta_{1}$, data points near to $\Theta_{1}$ $\left(0.06<\Theta<0.12 \mathrm{~m}^{3} \times \mathrm{m}^{-3}\right)$ were discarded. Data analysis resulted in $\beta=0.13 \pm 0.024 \mathrm{~K}^{-1}$ for the data points determined for $\Theta<0.06 \mathrm{~m}^{3} \mathrm{~m}^{-3}$, which is about the same as $\beta=0.12 \mathrm{~K}^{-1}$, determined for stress-free conditions within the error limits. Thus, no significant differences were found between the temperature dependency of emissions under drought-stress and under stress-free conditions.

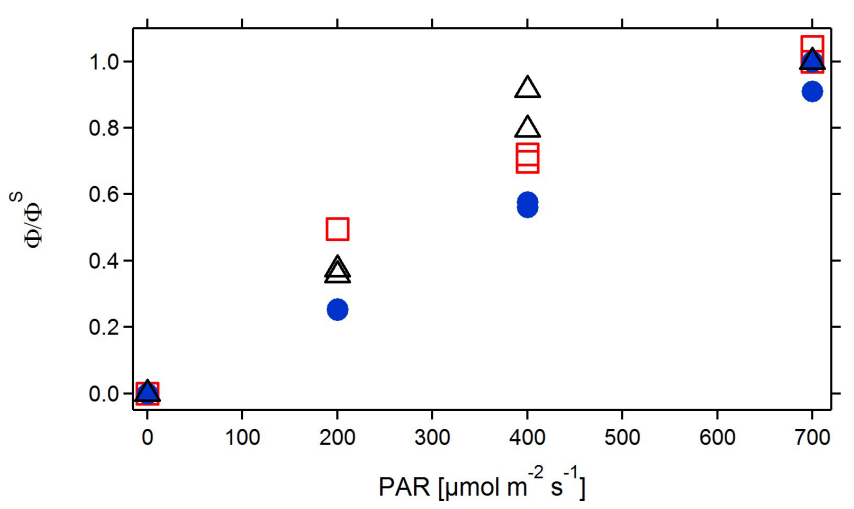

Figure 7. Emission rates corrected for the temporal decrease due to the progressing drought and normalized to the emission rates measured the respective day at PAR $=700 \mu \mathrm{mol} \mathrm{m}{ }^{-2} \mathrm{~s}^{-1}$ as a function of PAR. Blue circles represent data taken at $\Theta \sim 0.055 \mathrm{~m}^{3} \times \mathrm{m}^{-3}$, black triangles show data taken at $\Theta \sim 0.043 \mathrm{~m}^{3} \times \mathrm{m}^{-3}$ and red squares show the data obtained at $\Theta \sim 0.018 \mathrm{~m}^{3} \times \mathrm{m}^{-3}$. Experiment Holm oak 4, absolute emission rates measured at $700 \mu \mathrm{mol} \mathrm{m}{ }^{-2} \mathrm{~s}^{-1}$ dropped by a factor of about 40 with $\Theta$ falling from 0.055 to $0.018 \mathrm{~m}^{3} \times \mathrm{m}^{-3}$.

In the fourth experiment with Holm oak PAR was changed systematically during the progressing drought (Table 1, experiment Holm oak 4) to allow for determining the dependence of the emissions on $\Theta$ at different PAR and the dependence of emissions on PAR at progressing drought.

The correction was made in the same way as described above by fitting an exponential function to the temporal decay measured during the days at constant PAR and temperature. The emission rates measured the next day under conditions of variable PAR were then corrected by dividing them by the correction factors. The data already corrected for their $\Theta$ dependence were normalized using the emission rates measured at the respective day at $\mathrm{PAR}=700 \mu \mathrm{mol} \mathrm{m}^{-2} \mathrm{~s}^{-1}$. Figure 7 shows the normalized emission as a function of light intensity at the example of 3 days. Within the precision of the data the light intensity dependence did not substantially or systematically change with progressing drought.

\subsubsection{Scots pine and Norway spruce}

The experiments with pine and spruce lasted for about a month each and each of the plants was exposed to 3 drought periods. At least one of these drought applications was severe with $\Theta<0.01 \mathrm{~m}^{3} \times \mathrm{m}^{-3}$.

Main emissions from both conifers were pool MT emissions such as $\alpha$-pinene and $\Delta-3$-carene. Besides such pool emissions the plants also emitted 1,8-cineole which is a de novo emission (Tarvainen et al., 2005; Kleist et al., 2012). This was also tested for both individuals used in our experiments by exposing them to ${ }^{13} \mathrm{CO}_{2}$. After 3 hours of ${ }^{13} \mathrm{CO}_{2}$ exposure 1,8 -cineole was strongly labelled indicating that 1,8 -cineole was a de novo emission with 
negligible contribution of pool emissions. We here focus on the $\Theta$ dependence of 1,8-cineole in order to compare with results obtained for the de novo MT emissions from the deciduous species.

Emissions of 1,8-cineole from both species behaved similarly to the de novo MT emissions from the broadleaf species (compare Fig. S2 in the Supplement). When $\Theta$ dropped from $0.35 \mathrm{~m}^{3} \times \mathrm{m}^{-3}$ to the respective thresholds $\Theta_{1}$, the emissions slightly increased $(\sim 30 \%$ for spruce and $\sim 50 \%$ for pine). Below $\Theta_{1}$ the 1,8-cineole emissions decreased and approached nearly zero (compare Figs. S3 and S4). After rewatering, MT emissions recovered on a time scale of days and reached levels similar to those before the drought. All in all, the de novo emissions of pine and spruce behaved the same as the de novo MT emissions from the broadleaf species. Data of dependency of the 1,8-cineole emissions on $\Theta$ are listed in Table 2 together with the data obtained in the other experiments.

\section{Discussion}

\subsection{Comparison to literature data}

\subsubsection{Mild drought stress}

All de novo MT emissions from all plants investigated in our experiments were dependent on soil moisture. While mild drought $\left(\Theta>\Theta_{1}\right.$ with $\Theta_{1}=\Theta_{0}+\Delta \Theta_{1}$, see Table 2) caused slight increases of MT emissions, severe drought $\left(\Theta<\Theta_{1}\right)$ caused decreasing MT emissions from all investigated species.

Increasing emissions under mild drought have been reported before (Bertin and Staudt, 1996; Blanch et al., 2007; Ormeño et al., 2007). Blanch et al. (2007) studied MT emissions from Holm oak (Quercus ilex) and Aleppo pine (Pinus halepensis). They report emissions to increase twofold for Holm oak when the relative water content of the leaves decreases from $\sim 90$ to $80 \%$. Ormeño et al. (2007) studied the impact of water deficit on emissions from Rosemary (Rosmarinus officinalis), Aleppo pine (Pinus halepensis), Rock rose (Cistus albidus), and Kermes oak (Quercus coccifera). Using the plant water potential as a reference, they report two- to three-fold increases of MT emissions when the water potential drops from -2 to $-8 \mathrm{MPa}$.

Although these previous studies agree with our finding that MT emissions increase under mild drought, a quantitative comparison is impossible because different reference quantities are used to characterize the degree of drought stress. We assume that most of the increases in MT emissions observed during our studies were only an indirect effect of drought. In our studies leaf temperatures were reasonably well measured for the broadleaf species. Leaf temperatures increased when $\Theta$ dropped from high values $\left(\Theta>0.3 \mathrm{~m}^{3} \times \mathrm{m}^{-3}\right)$ to $\sim 0.1 \mathrm{~m}^{3} \times \mathrm{m}^{-3}$ even though chamber temperatures were kept constant. Obviously, the decline in transpiration lowered its cooling effect leading to higher leaf temperatures (Fig. 1). In the experiment with European beech and in three of the experiments with Holm oak (experiments 2, 3, and 4) MT emissions increased by less than $50 \%$ when leaf temperature increased due to the progressing drought. Applying $\beta$ $\sim 0.12 \mathrm{~K}^{-1}$, the main fraction of increases in MT emissions from these plants was explained by the increase of leaf temperature. Only for one single Holm oak we found an increase ( $\sim$ threefold, see Fig. 5b, red circles) too high to be explained by increases in leaf temperature alone.

Due to the watering-drought-watering procedure used here it is possible that parts of the increases arise from recovery from a preceding drought. In particular when $\Theta$ decreases rapidly, the effects of sequential droughts may overlap. However, the effect of strongly increasing MT emissions with $\Theta$ dropping from high levels to $\Theta_{1}$ was observed in one experiment only and without further information we can only speculate on this effect.

The reason for increases of the 1,8-cineole emissions from conifers during mild drought stress $(\sim 30-50 \%$ when $\Theta$ dropped from 0.35 to $0.1 \mathrm{~m}^{3} \mathrm{~m}^{-3}$ ) also remains unproven because leaf temperatures were not reliably measurable for both conifers. Nevertheless it is reasonable to assume that also in conifer species needle temperature increase due to lower transpirational cooling caused the observed slight increases in MT emissions.

For modelling of isoprene emissions in MEGAN, the impact of leaf temperature is implemented by a general temperature dependence of the emissions. Such parameterization cannot differentiate between variations of leaf temperature by variations in transpiration or by variations of air temperature. Therefore the indirect effect of drought does not appear in the factor for the dependence of isoprene emissions on soil moisture (Guenther et al., 2006). In analogy we suggest, to consider decreasing emissions caused by severe drought stress also for de novo MT emissions.

\subsubsection{Severe drought stress}

Similar to previous studies (e.g. Bertin and Staudt, 1996; Llusià and Peñuelas, 1998; Plaza et al., 2005; Lavoir et al., 2009; Šimpraga et al., 2011; Bourtsoukidis et al., 2014) we observed substantially reduced MT emissions during periods of severe drought as well as increasing emissions after re-watering (Peñuelas et al., 2009). Llusià and Peñuelas (1998) found strong suppression of MT emissions from non-storing species such as Holm oak and a significant relation between net assimilation and MT emissions. Lavoir et al. (2009) found exponentially decreasing emissions when the leaf-water potential fell below $-2 \mathrm{MPa}$. Šimpraga et al. (2011) show strong attenuation of MT emissions from European beech with progressing drought. The temporal shape of sabinene emissions from Beech as shown here in Fig. 3 for the second severe drought was nearly identical to the 
Table 2. Data from fits of emission rates vs. $\Theta$. EB $=$ European beech, $\mathrm{HO}=$ Holm oak, NS = Norway spruce, $\mathrm{SP}=\mathrm{Scots}$ pine. Numbers behind species indicate experiment number according to the succession of the experiments described in Sect. 3. Data behind the slash give chamber temperatures in ${ }^{\circ} \mathrm{C}$ and PAR in $\mu \mathrm{mol} \mathrm{m}{ }^{-2} \mathrm{~s}^{-1}$, respectively. $\Phi^{\text {th }}(\mathrm{MT})$ and $\Phi^{\text {th }}(\Sigma \mathrm{MT})$ are the emission rates measured for the MT listed in the second column and for the sum of all MT emissions, respectively as measured near to $\Theta_{1}$. $\Theta_{1}$ is the volumetric water content of the soil when emissions start to decrease $\left(\Theta_{1}=\Delta \Theta_{1}+\Theta_{0}\right)$. $\Theta_{0}=$ intercept of linear regression analysis when MT emissions are extrapolated to be zero. $\Delta \Theta_{1}$ is the range of $\Theta$ in which the emissions drop from their maximum to zero.

\begin{tabular}{llcccc}
\hline & MT & $\begin{array}{c}\Phi^{\text {th }}(\mathrm{MT}) \\
\left(\mathrm{nmol} \mathrm{m}^{-2} \mathrm{~s}^{-1}\right)\end{array}$ & $\begin{array}{c}\Phi^{\mathrm{th}}(\Sigma \mathrm{MT}) \\
\left(\mathrm{nmol} \mathrm{m}^{-2} \mathrm{~s}^{-1}\right)\end{array}$ & $\begin{array}{c}\Delta \Theta_{1} \\
\left(\mathrm{~m}^{3} \mathrm{~m}^{-3}\right)\end{array}$ & $\begin{array}{c}\Theta_{0} \\
\left(\mathrm{~m}^{3} \mathrm{~m}^{-3}\right)\end{array}$ \\
\hline EB & Sabinene & $0.9 \pm 0.03$ & $2.6 \pm 0.04$ & $0.09 \pm 0.004$ & $0.03 \pm 0.002$ \\
$\mathrm{HO} 1$ & $\alpha$-pinene & $4.9 \pm 0.45$ & $10.2 \pm 0.47$ & $0.044 \pm 0.004$ & $0.058 \pm 0.002$ \\
$\mathrm{HO} 2$ & $\alpha$-pinene & $2.1 \pm 0.05$ & $9.2 \pm 0.25$ & $0.063 \pm 0.003$ & $0.071 \pm 0.002$ \\
$\mathrm{NS}$ & 1,8 -cin. & $(3.3 \pm 1.1) \times 10^{-4}$ & $*$ & $0.19 \pm 0.01$ & $0.02 \pm 0.007$ \\
$\mathrm{SP}$ & 1,8 -cin. & $0.88 \pm 0.15$ & $*$ & $0.068 \pm 0.005$ & $0.041 \pm 0.004$ \\
$\mathrm{HO} / 15$ & $\alpha$-pinene & $3.5 \pm 0.08$ & $7.9 \pm 0.74$ & $0.055 \pm 0.01$ & $-0.006 \pm 0.007$ \\
$\mathrm{HO} 3 / 20$ & $\alpha$-pinene & $4.8 \pm 0.22$ & $11.7 \pm 0.6$ & $0.058 \pm 0.008$ & $-0.01 \pm 0.004$ \\
$\mathrm{HO} 3 / 25$ & $\alpha$-pinene & $6.5 \pm 0.34$ & $15.9 \pm 0.8$ & $0.079 \pm 0.016$ & $-0.021 \pm 0.008$ \\
$\mathrm{HO} 4 / 700$ & $\alpha$-pinene & $1.6 \pm 0.18$ & $6.7 \pm 0.8$ & $0.065 \pm 0.008$ & $0.016 \pm 0.006$ \\
$\mathrm{HO} 4 / 400$ & $\alpha$-pinene & $0.7 \pm 0.1$ & $2.6 \pm 0.4$ & $0.045 \pm 0.015$ & $0.018 \pm 0.012$ \\
$\mathrm{HO} 4 / 200$ & $\alpha$-pinene & $0.3 \pm 0.04$ & $1.2 \pm 0.17$ & $0.044 \pm 0.015$ & $0.019 \pm 0.012$ \\
\hline
\end{tabular}

* For the conifers, pure de novo emissions are of minor importance for the total emissions $\left(\Phi^{\text {th }}(\Sigma \mathrm{MT})=0.18 \mathrm{nmol} \mathrm{m}^{-2} \mathrm{~s}^{-1}\right.$ for spruce and $\Phi^{\text {th }}(\Sigma \mathrm{MT})=6.2 \mathrm{nmol} \mathrm{m}^{-2} \mathrm{~s}^{-1}$ for pine, both for the well watered individuals). Note that the formalism given here for the de novo emissions of European beech and Holm oak can be applied to individual MT as well as to $\Phi^{\text {th }}(\Sigma \mathrm{MT})$ whereas the formalism is only applicable to 1,8-cineole emissions from both conifers and not to the sum of MT emissions.

temporal shape observed by Šimpraga et al. (2011) indicating that the same general effect was found. But again, direct comparison of the results is not easy because different reference quantities are used to characterize the degree of drought.

Bourtsoukidis et al. (2014) use soil water availability to characterize the degree of drought. They measured BVOC emissions from Pedunculate oak (Quercus robur) and Black cherry (Prunus serotina). Compared to the MT emissions from regularly watered plants (soil water availability $~ 30 \%$ ) the MT emissions from plants under drought (soil water availability $\sim 2.3 \%$ ) were reduced by about $65 \%$. This is similar to the reductions found when taking the relative water content of the soil as a reference instead of $\Theta$.

As shown in Fig. 2, cross correlations including data obtained under severe drought led to excellent coefficients of determination implying that severe drought acts in the same manner on all MT. This can only be explained by two possibilities. Either drought suppresses all MT synthase activities in an identical manner, or affects a common precursor of all MT. While the former explanation is unlikely the latter is consistent to the findings of Grote et al. (2010) who show that MT synthase activities are unaffected by drought. The most probable explanation for the identical response of all MT emissions to the drought therefore is an impact on a common precursor.

\subsection{Present state of modelling with MEGAN}

While effects of soil moisture on de novo MT emissions are not yet considered in the Model of Emissions of Gases and Aerosols from Nature (MEGAN, Guenther et al., 2006, 2012) the effects on isoprene emissions are considered. As noted above, isoprene emissions are unaffected as long as $\Theta$ is above a threshold $\Theta_{1}$, they decrease linearly between $\Theta_{1}$ and the wilting point $\Theta_{\mathrm{W}}$ and they remain zero as long as $\Theta<\Theta_{\mathrm{W}}$. We found a similar behaviour for the de novo MT emissions indicating that the emission of MT on soil moisture can be modelled using the same formalism with the same basic modelling parameters $\Theta_{\mathrm{W}}$ and $\Delta \Theta_{1}$.

The wilting point $\Theta_{\mathrm{W}}$ is the soil moisture below which the plants cannot take up water. During our measurements we always observed a recovery of the plants from the drought after re-watering. Thus soil moisture during drought in our experiments must have been always slightly above a critical value causing permanent damage to the plant. Insofar $\Theta_{0}$ listed in Table 1 may not directly reflect $\Theta_{\mathrm{W}}$. However, $\Theta_{\mathrm{W}}$ depends on the soil and $\Theta_{\mathrm{W}}$ varies by up to 2 orders of magnitude (Chen and Dudhia, 2001). For modelling, $\Theta_{\mathrm{W}}$ data from Chen and Dudhia (2001) are used and such data are listed for different soil types. The data we provide for $\Theta_{0}$ are therefore not needed for modelling purposes and possible differences between $\Theta_{0}$ and $\Theta_{\mathrm{W}}$ are not relevant for modelling.

Basic parameter for modelling is $\Delta \Theta_{1}$. Our average of $\Delta \Theta_{1}$ (average $=0.08 \pm 0.05 \mathrm{~m}^{3} \times \mathrm{m}^{-3}$, error $=1 \sigma$ standard deviation, statistical weight the same for individual plants) is similar to $\Delta \Theta_{1}$ used to model isoprene emissions $\left(\Delta \Theta_{1}=0.06 \mathrm{~m}^{3} \times \mathrm{m}^{-3}\right)$. Our data for $\Delta \Theta_{1}$ show substantial variability and it is unknown so far whether the high variability is caused by a different behaviour of individuals or by other reasons. Within the uncertainty of the data it was 
also impossible to find differences between Holm oak and the other species. No conclusions can thus be drawn whether or not more drought tolerant plants such as Holm oak show different behaviour than more drought sensitive plants such as European beech. However, all plants behaved similarly and we therefore suggest that using the average $\Delta \Theta_{1}$ for modelling purposes is a tenable approach.

Considering the impact of soil moisture in MEGAN, results in a $7 \%$ reduction of global isoprene emissions only but substantial impacts of drought are expected on a regional scale (Guenther et al., 2006). In contrast Acosta Navarro et al. (2014) find significant depletion of global isoprene emissions by $24 \%$ when considering drought impacts.

Including the impacts of soil moisture on de novo MT emissions in modelling may have different effects because isoprene emitters and de novo MT emitters are regionally differently distributed. Recent studies show that, particularly in Europe, the fraction of MT emitting species is larger than previously predicted (Oderbolz et al., 2013; Kemper Pacheco et al., 2014). The effects described here may therefore have large impacts when modelling MT emissions in Europe.

Impacts of drought on MT emissions in Europe have been modelled by Lavoir et al. (2011). The authors performed model calculations to determine the impact of soil moisture on MT emissions from Holm oak in southern France. As input for their model they used data from Lavoir et al. (2009) who determined the soil moisture dependence of MT emissions from Holm oak using the leaf-water potential as the reference quantity. For modelling they used the relative water content of the soil (RWC) as reference considering a relationship between leaf-water potential and RWC. Lavoir et al. (2011) give a threshold of $0.7 \mathrm{~kg} \times \mathrm{kg}^{-1}$ above which MT emissions from Holm oak are independent of soil moisture and a linear decrease to zero at RWC $=0.4 \mathrm{~kg} \times \mathrm{kg}^{-1}$.

Using our data for Holm oak and applying our conversion factor (Eq. 7) we obtain $\mathrm{RWC}=0.24 \pm 0.1 \mathrm{~kg} \times \mathrm{kg}^{-1}$ as the threshold. The emissions are zero at RWC $\leq 0.09 \pm 0.1 \mathrm{~kg} \times \mathrm{kg}^{-1}$. Both our values are far lower than the data used by Lavoir et al. (2011) for up-scaling. Such differences are explainable by different structural properties of soils stressing the importance for regional models to consider soil properties for a more realistic emission estimate. However, the differences also show that the impacts of drought on regional MT emissions may be less pronounced than modelled by Lavoir et al. (2011).

\subsection{Use of $\Theta$ as the reference quantity for modelling}

We aimed at providing a data set to support modelling of soil moisture effects on de novo MT emissions with MEGAN. Therefore we used $\Theta$ as the reference quantity and we established an empirical relationship between de novo MT emissions and $\Theta$. Nevertheless, when reflecting mechanisms of the drought impact, plant physiological processes must be considered. For isoprene the decreasing emissions as result of drought are ascribed to a general decrease of the plant's performance (e.g. Brüggemann and Schnitzler, 2002). Decreased plant performance causes reduction of isoprene biosynthesis and thus isoprene emissions. Basic parts of isoprene and MT biosynthesis pathways are identical suggesting that general mechanisms causing the reduction of isoprene and MT emissions are similar. We therefore suggest that, similar to isoprene emissions, also the decrease of de novo MT emissions is caused by a general decrease of plant performance.

As plant performance is coupled to the rate of transpiration and to net assimilation either of them may be regarded as the reference quantity. But, as already pointed out by Peñuelas et al. (2009) and by Loreto and Schnitzler (2010), droughtinduced responses in transpiration or net assimilation differ from responses in MT emissions. This general behaviour was also found here in all experiments and we therefore could not use either of them as a reference quantity.

We used $\Theta$ as reference, but, from a mechanistic point of view $\Theta$ is not a direct reference quantity. In a first step, soil moisture impacts the plant performance and in a second step the plant performance affects MT synthesis and emissions. The relationship found here between de novo MT emissions and $\Theta$ therefore has to be scrutinized. In particular the temporal behaviour of MT emissions may be skewed by the time needed for the plant to respond to changes in $\Theta$.

Indeed there were time periods with substantial time lags between changes of $\Theta$ and the plants responses in MT emissions. Re-watering caused $\Theta$ to increase to optimum conditions for the plants on time scales of hours. For the de novo MT emissions, it took multiple days until the same level was reached as before the drought. We assume that the time needed for the plants to recover from previous droughts was the reason for the decoupling of $\Theta$ and MT emissions during such time periods.

Quick changes of $\Theta$ also appear in nature in case of strong rainfall. If such rainfall appears after a severe drought period with $\Theta$ being far below the threshold affecting emissions, $\Theta$ and emissions are most probably also decoupled in nature impeding a correct description of the emission temporal behaviour during such periods.

Whereas the increase of MT emissions during recovery after severe drought cannot be described by the formalism given here, impacts of soil moisture during desiccation can be described. Desiccation appears on longer time scales than changes of soil moisture after heavy rain fall. For such longer time scales, the lag between changes of $\Theta$ and the plants' response should not carry too much weight in skewing the relationship between emissions and $\Theta$. This assumption was confirmed by the result from the two experiments with Holm oak at different temporal progression of drought. Although the temporal decreases appeared on different time scales the $\Theta$ dependence of MT emissions remained similar (compare Figs. 5a and b). As long as desiccation appeared on a time scale of days, the plant responses to changes in $\Theta$ were 
obviously quick enough to allow finding the relationship between $\Theta$ and de novo MT emissions. Although $\Theta$ is only an indirect reference quantity for plant performance, it proved to be suitable for considering the impacts of soil moisture on de novo MT emissions in modelling.

We tested whether or not semi mechanistic models can be used to describe the impacts of soil moisture on MT emissions. In a first step we looked at the increase of MT emissions during recovery. Niinemets et al. (2002) couple de novo MT emissions to photosynthetic electron transport. They use the fraction of the photosynthetic electron transport necessary for MT synthesis $(\varepsilon)$ as a surrogate for standard emissions. By keeping $\varepsilon$ constant they closely couple isoprenoid emissions to photosynthesis. We tested this approach using the data from beech during a period of mild drought and rewatering when stomatal conductance was still reliably measurable (Fig. 3, days 0 to 11). From our data obtained during mild stress and recovery $\varepsilon$ was calculated as described in Niinemets et al. (2002). $\varepsilon$ was found to be constant during recovery, but increased for when $\Theta<0.2 \mathrm{~m}^{3} \mathrm{~m}^{-3}$, i.e. when photosynthesis already dropped but emissions were still not affected by the drought.

Constant $\varepsilon$ during recovery indicates a close coupling between photosynthesis and MT emissions during this period. Contrary, the decoupling of MT emissions from photosynthesis observed with $\Theta$ falling from 0.2 to $0.1 \mathrm{~m}^{3} \mathrm{~m}^{-3}$ disturbed the relationship between $\varepsilon$ and MT emissions.

Such decoupling was also observed for isoprene emissions and photosynthetic carbon supply and has been explained by the use of alternative carbon sources for isoprene biosynthesis (Possell and Loreto, 2013 and references cited therein). This may also be the reason for decoupling of MT emissions and photosynthesis. More improved semi mechanistic models (e.g. Morfopoulos et al., 2013, 2014; Grote et al., 2014) allow varying the fraction of electron transport used for MT synthesis. Such variation is requested by our results and indeed, the dependence of MT emissions on soil moisture as shown by Grote et al. (2014) matches our findings better than a description with fixed electron transport. Nevertheless, there are still differences between our data and the model predictions. Our data show a substantial shift with sustained MT emissions at already strongly suppressed net photosynthesis. Even improved semi-mechanistic models overestimate the impacts of drought on de novo MT emissions. In particular the later reactions of MT emissions compared to the reactions in net photosynthesis (e.g. Fig. 4) should be taken into account. In units of $\Theta$ this shift is in the range of $0.09 \mathrm{~m}^{3} \times \mathrm{m}^{-3}$ and in units of RWC about $0.23 \mathrm{~kg} \times \mathrm{kg}^{-1}$.

\subsection{Justification of a multiplicative approach for modelling}

Modelling BVOC emissions is often performed using factorial approaches. An important requirement for the validity of such a factorial approach is a negligible interdependency of the individual factors. We investigated such possible interdependencies but no substantial effects were found.

As can be seen from Fig. 6, the temperature dependence of MT emissions from Holm oak was largely independent of the actual $\Theta$. Vice versa, the soil moisture dependence of the emissions was independent of the actual temperature (compare data in Table 2). Also the PAR dependence of MT emissions from this species was not substantially affected by the actual soil moisture (Fig. 7) and vice versa the $\Theta$ dependence was not substantially influenced by PAR (Table 2 ). Compared to the overall effect of drought on de novo MT emissions, possible residual interdependencies were negligible. This indicates that a factorial approach is justified at least for Holm oak investigated with this respect. From the similarity of basic processes leading to de novo MT emissions we postulate that such interdependencies are also negligible for other plant species.

\section{Conclusions}

All de novo MT emissions from all plants investigated in our experiments clearly depended on soil moisture. The investigated species are representative for European climate zones and they all are strong MT emitters. We therefore conclude that impacts of drought have to be re-considered for modelling.

To the best of our knowledge, the direct impacts of soil moisture on constitutive de novo MT emissions are not considered in MEGAN. Severe drought reduces the emissions and therefore models neglecting impacts of soil moisture overestimate MT emissions. Depending on the climatology in the respective regions and depending on the fraction of de novo emitted MT, modelled MT emissions may drop substantially when considering soil moisture as variable influencing de novo MT emissions.

On the other hand, to the best of our knowledge semi mechanistic models overpredict the impacts of drought on de novo MT emissions. Again, depending on the climatology of the respective regions and the fraction of de novo emitters in the respective region, modelled de novo MT emissions may increase substantially. Large differences of modelling results for MT emissions (Arneth et al., 2008) may therefore be reduced to some extent.

Although the detailed mechanisms causing the reductions in de novo MT emissions are still unknown, one statement can be made. Estimations of future alterations of MT emissions must consider such effects because climate change may induce more and longer lasting drought periods (Dai, 2013). Future long lasting drought periods will suppress constitutive de novo MT emissions. In combination with more intensive heat periods that negatively affect de novo MT emissions (Kleist et al., 2012), these abiotic stresses will have substantial impacts on regional and global BVOC emissions. 


\section{The Supplement related to this article is available online at doi:10.5194/bg-12-177-2015-supplement.}

Acknowledgements. The authors would like to acknowledge financial support by the integrated EU project ECLAIRE (Contract no. 282910).

The service charges for this open access publication have been covered by a Research Centre of the Helmholtz Association.

Edited by: T. Keenan

\section{References}

Acosta Navarro, J. C., Smolander, S., Struthers, H., Zorita, E., Ekman, A. M. L., Kaplan, J. O., Guenther, A., Arneth, A., and Riipinen, I., Global emissions of terpenoid VOCs from terrestrial vegetation in the last millennium, J. Geophys. Res. Atmos., 119, 6867-6885, 2014.

Arneth, A., Monson, R. K., Schurgers, G., Niinemets, Ü., and Palmer, P. I.: Why are estimates of global terrestrial isoprene emissions so similar (and why is this not so for monoterpenes)?, Atmos. Chem. Phys., 8, 4605-4620, doi:10.5194/acp-8-46052008, 2008.

Bertin, N. and Staudt, M.: Effect of water stress on monoterpene emissions from young potted holm oak (Quercus ilex L.) trees, Oecologia, 107, 456-462, 1996.

Blanch, J.-S., Peñuelas, J., and Llusià, J.: Sensitivity of terpene emissions to drought and fertilization in terpene-storing $\mathrm{Pi}$ nus halepensis and non-storing Quercus ilex, Physiol. Plant., 131, 211-225, 2007.

Bourtsoukidis, E., Kawaletz, H., Radacki, D., Schütz, S., Hakola, H., Hellén, H., Noe, S., Mölder, I., Ammer, C., and Bonn, B.: Impact of flooding and drought conditions on the emission of volatile organic compounds of Quercus robur and Prunus serotina, Trees, 28, 93-204, 2014.

Brüggemann, N. and Schnitzler, J. P.: Comparison of isoprene emission, intercellular isoprene concentration and photosynthetic performance in water-limited oak (Quercus pubescens Willd. and Quercus robur L.) saplings, Plant Biol., 4, 456-463, 2002.

Chameides, W. L., Lindsay, R. W., Richardson, J., and Kiang, C. S.: The role of biogenic hydrocarbons in urban photochemical smog: Atlanta as a case study, Science, 241, 1473-1475, 1988.

Chen, F. and Dudhia, J.: Coupling an Advanced Land Surface Hydrology Model with the Penn State - NCAR MM5 Modeling System. Part I: Model Implementation and Sensitivity, Monthly Weather Rev., 129, 569-585, 2001.

Dai, A.: Increasing drought under global warming in observations and models, Nat. Clim. Change, 3, 52-58, 2013.

Derwent, R. G., Jenkin, M. E., and Saunders, S. M.: Photochemical ozone creation potentials for a large number of reactive hydrocarbons under European conditions, Atmos. Environ., 30, 181-199, 1996.
Grote, R., Keenan, T., Lavoir, A.-V., and Staudt, M.: Process-based simulation of seasonality and drought stress in monoterpene emission models, Biogeosciences, 7, 257-274, doi:10.5194/bg7-257-2010, 2010.

Grote, R., Morfopoulos, C., Niinemets, Ü., Sun, Z., Keenan, T. F., Pacifico, F., and Butler T.: A fully integrated isoprenoid emissions model coupling emissions to photosynthetic characteristics, Plant Cell Environ., 37, 1965-1980, 2014.

Guenther, A., Hewitt, C. N., Erickson, D., Geron, C., Graedel, T., Harley, P., Klinger, L., Lerdau, M., McKay, W. A., Pierce, T., Scholes, B., Steinbrecher, R., Tallamraju, R., Taylor J., and Zimmerman, P.: A global model of natural volatile organic compound emissions, J. Geophys. Res., 100, 8873-8892, 1995.

Guenther, A. B., Zimmerman, P. R., Harley, P. C., Monson, R. K., and Fall, R.: Isoprene and monoterpene emission rate variability: Model Evaluation and sensitivity analyses, J. Geophys. Res., 98, 12609-12617, 1993.

Guenther, A. B., Karl, T., Harley, P., Wiedinmyer, C., Palmer, P. I., and Geron, C.: Estimates of global terrestrial isoprene emissions using MEGAN (Model of Emissions of Gases and Aerosols from Nature), Atmos. Chem. Phys., 6, 3181-3210, doi:10.5194/acp-63181-2006, 2006.

Guenther, A. B., Jiang, X., Heald, C. L., Sakulyanontvittaya, T., Duhl, T., Emmons, L. K., and Wang, X.: The Model of Emissions of Gases and Aerosols from Nature version 2.1 (MEGAN2.1): an extended and updated framework for modeling biogenic emissions, Geosci. Model Dev., 5, 1471-1492, 2012.

Heiden, A. C., Kobel, K., Langebartels, C., Schuh-Thomas, G., and Wildt, J.: Emissions of oxygenated compounds from plants, Part I: Emissions from Lipoxygenase activity, J. Atmos. Chem., 45, 143-172, 2003.

Jacob, D. J. and Wofsy, S. C.: Photochemistry of biogenic emissions over the Amazon forest, J. Geophys. Res., 93, 1477-1486, 1988.

Kemper Pacheco, C., Fares, S., and Ciccioli, P.: A highly spatially resolved GIS-based model to assess the isoprenoid emissions from key Italian ecosystems, Atmos. Environ., 96, 50-60, 2014.

Kleist, E., Mentel, T. F., Andres, S., Bohne, A., Folkers, A., Kiendler-Scharr, A., Rudich, Y., Springer, M., Tillmann, R., and Wildt, J.: Irreversible impacts of heat on the emissions of monoterpenes, sesquiterpenes, phenolic BVOC and green leaf volatiles from several tree species, Biogeosciences, 9, 51115123, doi:10.5194/bg-9-5111-2012, 2012.

Kulmala, M., Vehkamäki, H., Petäjä, T., Dal Maso, M., Lauri, A., Kerminen, V. N., Birmili, W., and McMurry, P. H.: Formation and growth rates of ultrafine atmospheric particles: a review of observations, J. Aerosol Science, 35, 143-176, 2004.

Lavoir, A.-V., Staudt, M., Schnitzler, J. P., Landais, D., Massol, F., Rocheteau, A., Rodriguez, R., Zimmer, I., and Rambal, S.: Drought reduced monoterpene emissions from the evergreen Mediterranean oak Quercus ilex: results from a throughfall displacement experiment, Biogeosciences, 6, 1167-1180, doi:10.5194/bg-6-1167-2009, 2009

Lavoir, A. V., Duffet C., Mouillot F., Rambal S., Ratte J. P., Schnitzler J. P., and Staudt M.: Scaling-up leaf monoterpene emissions from a water limited Quercus ilex woodland, Atmos. Environ., 45, 2888-2897, 2011.

Llusià, J. and Peñuelas J.: Changes in terpene content and emission in potted mediterranean woody plants under severe drought, Can. J. Botany, 76, 1366-1373, 1998. 
Loreto, F. and Schnitzler, J.P.: Abiotic stresses and induced BVOCs, Trends Plant Sci., 15, 154-166, 2010.

Mentel, Th. F., Wildt, J., Kiendler-Scharr, A., Kleist, E., Tillmann, R., Dal Maso, M., Fisseha, R., Hohaus, Th., Spahn, H., Uerlings, R., Wegener, R., Griffiths, P., Dinar, E., Rudich, Y., and Wahner, A.: Photochemical production of aerosols from real plant emissions, Atmos. Chem. Phys., 9, 4387-4406, 2009,

http://www.atmos-chem-phys.net/9/4387/2009/.

Mentel, Th. F., Kleist, E., Andres, S., Dal Maso, M., Hohaus, T., Kiendler-Scharr, A., Rudich, Y., Springer, M., Tillmann, R., Uerlings, R., Wahner, A., and Wildt, J.: Secondary aerosol formation from stress-induced biogenic emissions and possible climate feedbacks, Atmos. Chem. Phys., 13, 8755-8770, doi:10.5194/acp-13-8755-2013, 2013.

Morfopoulos, C., Prentice, I. C., Keenan, T. F., Friedlingstein, P., Medlyn, B. E., Peñuelas, J., and Possell, M.: A unifying conceptual model for the environmental responses of isoprene emissions from plants, Ann. Bot., 112, 1223-1238, 2013.

Morfopoulos, C., Sperlich, D., Peñuelas, J., Cubells, I. F., Llusià, J., Medlyn, B. E., Niinemets, Ü., Possell M., Sun, Z., and Prentice, I. C.: A model of plant isoprene emission based on available reducing power captures responses to atmospheric $\mathrm{CO}_{2}$, New Phytol., 203, 125-139, 2014.

Niinemets, Ü., Seufert, G., Steinbrecher, R., and Tenhunen, J. D.: A model coupling foliar monoterpene emissions to leaf photosynthetic characteristics in Mediterranean evergreen Quercus species, New Phytol., 153, 257-275, 2002.

Oderbolz, D. C., Aksoyoglu, S., Keller, J., Barmpadimos, I., Steinbrecher, R., Skjøth, C. A., Plaß-Dülmer, C., and Prévôt, A. S. H.: A comprehensive emission inventory of biogenic volatile organic compounds in Europe: improved seasonality and landcover, Atmos. Chem. Phys., 13, 1689-1712, doi:10.5194/acp-131689-2013, 2013,

Ormeño, E., Mévy, J. P., Vila, B., Bousquet-Mélou, A., Greff, S., Bonin, G., and Fernandez, C.: Water deficit stress induces different monoterpene and sesquiterpene emission changes in Mediterranean species. Relationship between terpene emissions and plant water potential, Chemosphere, 67, 276-284, 2007.

Pegoraro, E., Rey, A., Bobich, E. G., Barron-Gafford, G., Grieve, A., Malhi, Y., and Murthy, R.: Effect of elevated $\mathrm{CO}_{2}$ concentration and vapor pressure deficit on isoprene emission from leaves of Populus deltoides during drought, Funct. Plant Biol., 31, 1137-1147, 2004.

Peñuelas, J., Filella, I., Seco, R., and Llusià J.: Increase in isoprene and monoterpene emissions after re-watering of droughted Quercus ilex seedlings, Biologia plantarum, 53, 351-354, 2009.

Plaza, J., Núñez, L., Pujadas, M., Pérez-Pastor, R., Bermejo, V., García-Alonso, S., and Elvira, S.: Field monoterpene emission of Mediterranean oak (Quercus ilex) in the central Iberian Peninsula measured by enclosure and micrometeorological techniques: Observation of drought stress effect, J. Geophys. Res., 110, D03303, doi:10.1029/2004JD005168, 2005.
Possell, M. and Loreto, F.: The Role of Volatile Organic Compounds in Plant Resistance to Abiotic Stresses: Responses and Mechanisms, in: Biology, Controls and Models of Tree Volatile Organic Compound Emissions, edited by: Niinemets, Ü. and Monson, R. K., Springer Netherlands, 209-235, 2013.

Rambal, S., Ourcival, J. M., Joffre, R., Mouillot, F., Nouvellon, Y., Reichstein, M., and Rocheteau, A.: Drought controls over conductance and assimilation of a Mediterranean evergreen ecosystem: scaling from leaf to canopy, Glob. Change Biol., 9, 18131824, 2003.

Schimang, R., Folkers, A., Kleffmann, J., Kleist, E., Miebach, M., and Wildt, J.: Uptake of gaseous nitrous acid (HONO) by several plant species, Atmos. Environ., 40, 1324-1335, 2006.

Schuh, G., Heiden, A. C., Hoffmann, T., Kahl, J., Rockel, P., Rudolph, J., and Wildt, J.: Emissions of volatile organic compounds from sunflower and beech: Dependence on temperature and light intensity, J. Atmos. Chem., 27, 291-318, 1997.

Shao, M., v.Czapiewski, K., Heiden, A. C., Kobel, K., Komenda, M., Koppmann, R., and Wildt, J.: Volatile organic compound emissions from Scots pine: Mechanisms and description by algorithms, J. Geophys. Res., 106, 20483-20491, 2001.

Šimpraga M., Verbeeck, H., Demarcke, M., Joó, É., Pokorska, O., Amelynck, C., Schoon, N., Dewulf, J., Van Langenhove, H., Heinesch, B., Aubinet, M., Laffineur, Q., Müller, J.-F., and Steppe, K.: Clear link between drought stress, photosynthesis and biogenic volatile organic compounds in Fagus sylvatica L., Atmos. Environ., 45, 5254-5259, 2011.

Staudt, M. and Bertin, N.: Light and temperature dependence of the emission of cyclic and acyclic monoterpenes from Holm Oak (Quercus ilex L.) leaves, Plant Cell Environ., 21, 385-395, 1998.

Tarvainen, V., Hakola, H., Hellén, H., Bäck, J., Hari, P., and Kulmala, M.: Temperature and light dependence of the VOC emissions of Scots pine, Atmos. Chem. Phys., 5, 989-998, doi:10.5194/acp-5-989-2005, 2005.

Tingey, D. T., Manning, M., Grothaus, L. C., and Burns, W. F.: Influence of light and temperature on monoterpene emission rates from Slash Pine, Plant Physiol., 65, 797-801, 1980.

Tingey, D. T., Turner, D. P., and Weber, J. A.: Factors controlling the emissions of monoterpenes and other volatile organic compounds, in: Trace Gas Emissions by Plants, edited by: Sharkey, T. D., Holland, E. A., Mooney, H. A., Academic Press, 93-119, 1991.

Wildt, J., Kley, D., Rockel, A., Rockel, P., and Segschneider, H. J.: Emission of NO from several higher plant species, J. Geophys. Res., 102, 5919-5927, 1997. 